\title{
The Metabolic Functions of Carnitine in Torulopsis bovina
}

\author{
By LAWRENCE M. LEWIN \\ Department of Chemical Pathology, Sackler School of Medicine, Tel Aviv University, \\ Tel HaShomer, Israel
}

(Received 30 May 1984; revised 6 December 1984)

The carnitine-responsive mutant yeast Torulopsis bovina ATCC 26014, when grown on medium supplemented with carnitine, contained acetyl- and propionylcarnitines, consistent with the presence of carnitine acetyltransferase, which catalyses the reaction carnitine + acyl-CoA $\rightleftharpoons$ acylcarnitine $+\mathrm{CoA}$. Two hypotheses for the metabolic function of carnitine were tested. (1) That by reacting with acyl-CoA and releasing $\mathrm{CoA}$, carnitine decreases the requirement for CoA. The effect of carnitine on the growth of the organism was measured in medium containing limiting amounts of pantothenate, which is a component of CoA. Carnitine did not increase the cell yield, suggesting that it did not exert a pantothenate-sparing effect. (2) That carnitine facilitates utilization of short-chain fatty acids. Carnitine reversed the growth inhibition which occurred when acetate was present in the medium, and also increased the respiration rate when acetate was the substrate, results consistent with the hypothesis that the carnitine acetyltransferase system was the limiting factor in transport of acetyl groups into mitochondria of $T$. bovina ATCC 26014.

The properties of the carnitine-responsive strain were compared with those of the wild-type, $T$. bovina ATCC 22987. Growth rate of the wild-type was rapid and was not stimulated by carnitine, nor was it inhibited by acetate in the growth medium. Acetate increased the respiration rate of the wild-type to the same extent in the presence or absence of carnitine. It is postulated that the mutant lacks a mechanism for handling acetate which is present in the wildtype, and that addition of carnitine to the medium enables the carnitine acetyltransferase system of the mutant to increase the rate of transport of acetyl groups into the mitochondria.

\section{INTRODUCTION}

The carnitine-responsive strain of Torulopsis bovina, ATCC 26014 (also called Candida pintolopesii) was originally isolated from a choline-requiring strain and was used for a microbiological assay for carnitine (Travassos \& Sales, 1974). The present study was conducted to evaluate possible metabolic functions of carnitine in strain ATCC 26014 in the light of the following facts.

L-Carnitine (a quaternary ammonium compound) plays an important role in fatty acid oxidation by forming long-chain acylcarnitine derivatives which transport fatty acyl groups into mitochondria (Fritz, 1963). Although carnitine stimulates growth of T. bovina ATCC 26014, the only carnitine derivatives that have been detected in the cells of this yeast are acetyl-, propionyland traces of four-carbon acyl esters (Lewin \& Golan, 1983), consistent with the report that carnitine acetyltransferase is present in this organism, and that it does not oxidize palmitate, nor contain carnitine acyltransferases with specificity for long- or medium-chain length fatty acylCoAs (Bieber et al., 1980). Since T. bovina ATCC 26014 can use carnitine only for processes involving short-chain acylcarnitines, it is an excellent test organism for studying the metabolic functions of the carnitine acetyltransferase system. This enzyme (EC 2.3.1.7) catalyses the reaction of L-carnitine with short-chain acyl-CoAs to form acylcarnitine and CoA, with the following specific activities relative to acetyl-CoA ( 100$)$ : propionyl-CoA, 111; n-butyryl-CoA, 12; isobutyryl-CoA, 28 (Emaus \& Bieber, 1983). 
Pearson \& Tubbs (1967) have suggested that carnitine might play a significant role in cellular metabolism by reacting with acetyl-CoA to release $\mathrm{CoA}$ and, in this way, buffer the ratio of acetyl-CoA and CoA. In monkey sperm cells Casillas \& Erickson (1975) reported a total carnitine concentration 1000-fold higher than the total CoA concentration, thus allowing carnitine acetyltransferase to play a significant role in this buffering action. Likewise, Snoswell \& Koundakjian (1972) reported that a $50 \mathrm{~kg}$ sheep could theoretically 'store' $6 \mathrm{~g}$ acetyl groups as acetylcarnitine, thus releasing $\mathrm{CoA}$ for other metabolic purposes. Because $\mathrm{CoA}$ is produced from the vitamin pantothenic acid, such a release of $\mathrm{CoA}$ might reduce the amount of pantothenate required per cell. Another hypothesis suggests that the carnitine acetyltransferase system is necessary for transporting short-chain acyl groups through the yeast inner mitochondrial membrane by a mechanism similar to that used for the long-chain acyl esters (Kohlhaw \& Tan-Wilson, 1977).

In the studies reported here I investigated the interactions between growth stimulation by carnitine and pantothenate in $T$. bovina and studied the effect of carnitine on the test organism in the presence of acetate, propionate, butyrate and isobutyrate.

\section{METHODS}

The carnitine-responsive yeast strain Torulopsis bovina ATCC 26014 and the wild-type strain T. bovina ATCC 22987 were obtained from the American Type Culture Collection, Rockville, Md., USA. Cells were maintained, inocula were prepared and bioautography was done as described by Lewin \& Bieber (1979). For production of cell extracts the yeasts were grown in bioautography medium without agar, containing $0 \cdot 16 \%$ glucose and DL-carnitine. $\mathrm{HCl}\left(1 \mathrm{mg} \mathrm{l}^{-1}\right)$ with the addition of various test substances as described in the text, and incubated at $28^{\circ} \mathrm{C}$ for $2 \mathrm{~d}$ before harvest by centrifugation. The cell pellet was washed by resuspension in saline and the cells were recovered by centrifugation. After three washes, the cell pellet was frozen and thawed three times by placing the tube alternately in a dry ice/acetone mixture and in tepid water. Ethanol (absolute, 4 vols) was added to the cell pellet and the resulting extract was chromatographed, descending, on Whatman no. 1 paper, using the solvent system $n$-butanol/glacial acetic acid/water $(8: 1: 1$, by vol.) prior to bioautography.

Growth rates were measured in $100 \mathrm{ml}$ portions of the microbiological assay medium of Travassos \& Sales (1974) modified as described in the text. Cultures were grown in bottles $(500 \mathrm{ml})$ fitted with caps containing cuvettes ( $18 \mathrm{~mm}$ diam.) suitable for use with the Coleman Jr II spectrophotometer. Incubation, with shaking, was at $28^{\circ} \mathrm{C}$, and growth was measured as $\mathrm{OD}_{600}$.

Cells to be used for studies of respiration were grown in $50 \mathrm{ml}$ portions of the sterile medium of Travassos \& Sales (1974) modified to contain $0.1 \%$ glucose, in cotton-stoppered Erlenmeyer flasks $(250 \mathrm{ml})$, at $28-30{ }^{\circ} \mathrm{C}$ with shaking. After $22 \mathrm{~h}$ cells were harvested by centrifugation, washed twice with saline $(0.9 \%)$ and then suspended in a salts mixture $\left(\mathrm{KH}_{2} \mathrm{PO}_{4}, 0.5 \mathrm{~g} \mathrm{l}^{-1} ; \mathrm{MgSO}_{4} .7 \mathrm{H}_{2} \mathrm{O}, 0.5 \mathrm{~g} \mathrm{l}^{-1} ; \mathrm{NaCl}, 0.8 \mathrm{~g} \mathrm{l}^{-1}\right)$ to a cell density of 3 to $6 \times 10^{6}$ cells $\mathrm{ml}^{-1}$. The rates of oxygen utilization of samples $(3 \mathrm{ml})$ of these suspensions were measured, at $37^{\circ} \mathrm{C}$, before and after addition of various substances described in the text, using the YSI model 53 Oxygen Monitor (Yellow Springs Instrument Corp., Yellow Springs, Ohio, USA) attached to a Servogor 120 recorder (BBC, Goerz, Austria). Oxygen utilization was calculated as $\mathrm{nmol} \mathrm{O}_{2} \mathrm{~h}^{-1}$ per $10^{6}$ cells, based on a saturation value of $217 \mathrm{nmol} \mathrm{O}_{2} \mathrm{ml}^{-1}$ at $37^{\circ} \mathrm{C}$.

\section{RESULTS}

When T. bovina ATCC 26014 was grown in the presence of carnitine with glucose as the major carbon source the cells contained carnitine and acetylcarnitine with smaller amounts of propionylcarnitine, as shown by bioautography. Addition of propionate to the growth medium resulted in an increase in propionylcarnitine and supplementation with n-butyrate or isobutyrate resulted in production of 4-carbon chain acylcarnitines (Fig. 1a). Addition to the medium of fatty acids of chain lengths of five carbon atoms or more did not result in the appearance of corresponding longer-chain acylcarnitines. Addition of Tween 20, 40,60 or 80, which contain polyoxyethylene sorbitan esters of lauric, palmitic, stearic and oleic acids, respectively, did not result in the appearance of zones with $R_{F}$ values characteristic of long-chain carnitine esters in bioautograms of the cell extracts. These findings indicated that the cells were able to form carnitine esters of fatty acids with two to four carbon atoms but were unable to esterify carnitine with longer-chain fatty acids. 


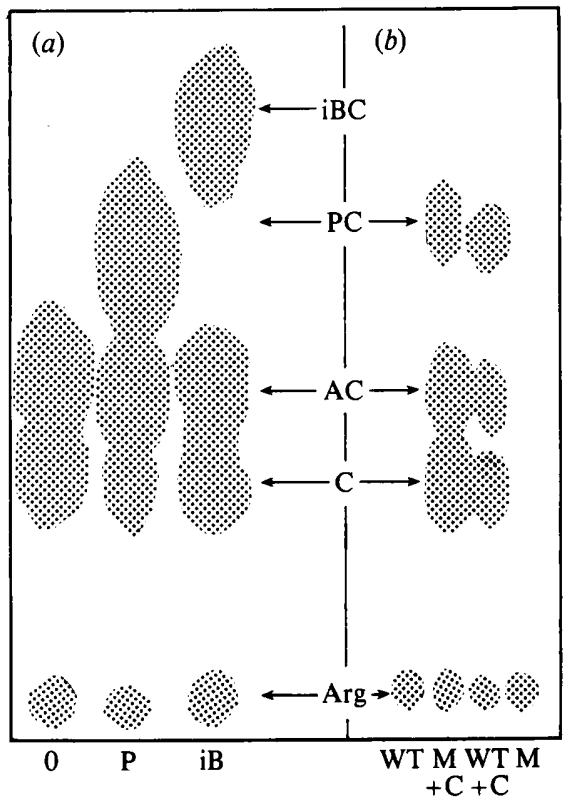

Fig. 1. A drawing of a bioautogram of cell extracts of Torulopsis bovina, showing the response to carnitine and its derivatives. (a) $T$. bovina ATCC 26014 was grown in medium containing DLcarnitine. $\mathrm{HCl}\left(1 \mathrm{mgl}^{-1}\right)$ without addition (0), or with the addition of buffered ( $\mathrm{pH} 5$ ) sodium propionate ( $\mathrm{P}$; to $0.02 \%$ final concentration) or sodium isobutyrate (iB; to $0.02 \%$ ). Cell extracts were chromatographed and bioautographed as described by Lewin \& Bieber (1979). (b) Wild-type (WT; ATCC 22987) and mutant (M; ATCC 26014) T. bovina were grown on carnitine-free medium or on medium supplemented with DL-carnitine. $\mathrm{HCl}\left(+\mathrm{C} ; 1 \mathrm{mg} \mathrm{l}^{-1}\right)$. Samples $(10 \mu \mathrm{l})$ of cell extracts were chromatographed and bioautographed. Chromatographic mobilities were compared with those of arginine (Arg), carnitine (C), acetylcarnitine (AC), propionylcarnitine (PC) and isobutyrylcarnitine (iBC).

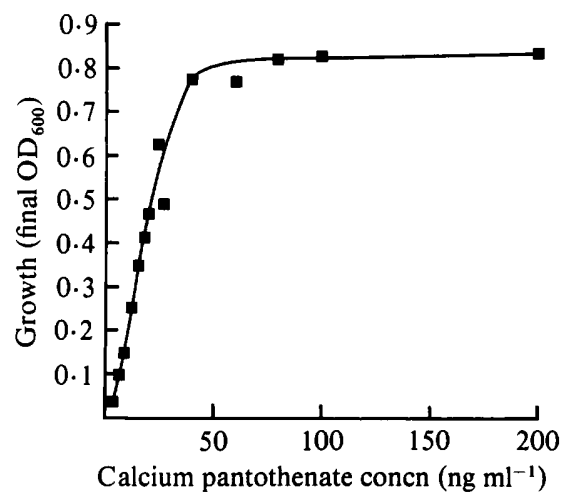

Fig. 2. Effect of calcium pantothenate on growth of $T$. bovina ATCC 26014. The yeast was grown for $23 \mathrm{~h}$ at $28^{\circ} \mathrm{C}$, with shaking, in Erlenmeyer flasks containing $10 \mathrm{ml}$ of the microbiological assay medium of Travassos \& Sales (1974) supplemented with DL-carnitine. $\mathrm{HCl}\left(2 \mathrm{mg} \mathrm{l}^{-1}\right)$ but lacking calcium pantothenate except for the varying amounts shown in the figure.

Preliminary results showed that $T$. bovina ATCC 26014 has absolute requirements for pantothenate, thiamin and nicotinic acid. Further studies showed that calcium pantothenate was growth limiting in concentrations up to approximately $30 \mathrm{ng} \mathrm{ml}^{-1}$ (Fig. 2). Pantothenate is a component not only of CoA but also of the fatty acid synthase system which is responsible for biosynthesis of palmitic acid. In order to establish conditions in which CoA was the growthlimiting metabolite the yeast was grown in media which contained polyoxyethylenesorbitan 


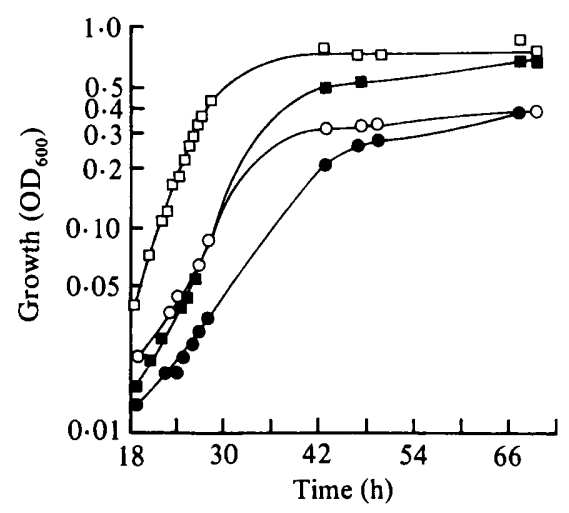

Fig. 3

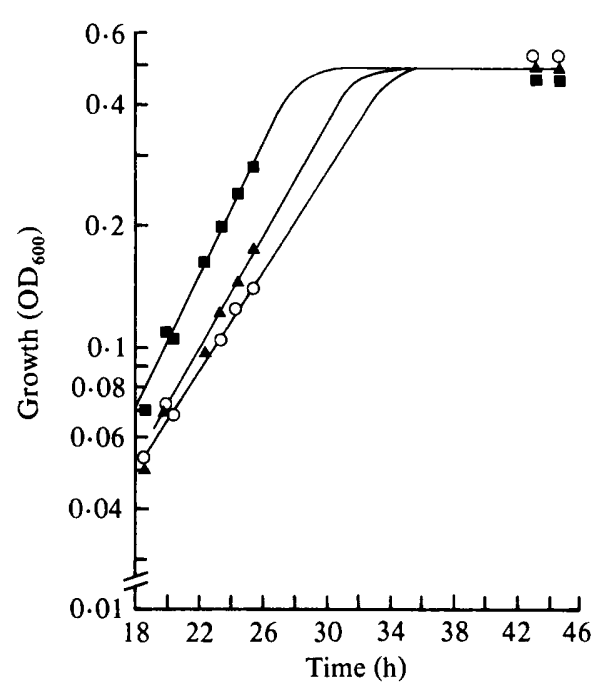

Fig. 4

Fig. 3. Effect of carnitine supplementation on growth of $T$. bovina ATCC 26014 in the presence of limiting amounts of calcium pantothenate. The yeast was grown at $28^{\circ} \mathrm{C}$, with shaking, in the medium of Travassos \& Sales (1974) supplemented with Tween $40\left(2.6 \mathrm{~g} \mathrm{l}^{-1}\right)$, calcium chloride (to $\left.0.05 \mathrm{M}\right)$ and calcium pantothenate (at either $5 \mathrm{ng} \mathrm{m}^{-1}$ or $15 \mathrm{ng} \mathrm{ml}^{-1}$ as specified), with or without addition of DLcarnitine. $\mathrm{HCl}\left(2 \mathrm{mg} \mathrm{l}^{-1} ; 10 \cdot 1 \mu \mathrm{M}\right)$, and $\mathrm{OD}_{600}$ was measured. $\square$, $\square$, Calcium pantothenate at $15 \mathrm{ng} \mathrm{ml}^{-1}(0.063 \mu \mathrm{M})$ in medium containing carnitine $(\square)$ or without it $(\square) . \bigcirc, \bigcirc$, Calcium pantothenate at $5 \mathrm{ng} \mathrm{m}^{-1}(0.021 \mu \mathrm{M})$ in medium containing carnitine $(\mathrm{O})$ or without it $(O)$.

Fig. 4. Effect of varying carnitine concentrations on growth of T. bovina ATCC 26014. The yeast was grown as described for Fig. 3, with limiting calcium pantothenate $\left(10 \mathrm{ng} \mathrm{ml}^{-1}\right)$ and varying concentrations of $\mathrm{DL}$-carnitine. $\mathrm{HCl}\left(\mathrm{O}\right.$, no carnitine; $\left.\boldsymbol{\Delta}, 2 \mathrm{ng} \mathrm{ml}^{-1} ; \square, 2000 \mathrm{ng} \mathrm{ml}^{-1}\right)$.

\section{Table 1. Effect of short-chain fatty acids on growth rate of $T$. bovina}

The yeasts were grown on the medium of Travassos \& Sales (1974), unsupplemented or supplemented with sodium salts of the short-chain fatty acids shown, buffered to $\mathrm{pH} 5.0$ and adjusted to $25 \mathrm{~mm}$ final concentration. Generation time $\left( \pm\right.$ SEM) was defined as minutes required for the $\mathrm{OD}_{600}$ to double during the exponential phase of growth.

\begin{tabular}{|c|c|c|c|c|}
\hline \multirow[b]{2}{*}{ Strain } & \multirow[b]{2}{*}{$\begin{array}{l}\text { Compound } \\
\text { added }\end{array}$} & \multirow[b]{2}{*}{$\begin{array}{l}\text { No. of } \\
\text { replicates }\end{array}$} & \multicolumn{2}{|c|}{ Generation time (min) } \\
\hline & & & $\begin{array}{c}\text { No } \\
\text { carnitine }\end{array}$ & $\begin{array}{l}\text { DL-Carnitine. } \mathrm{HCl} \\
\quad\left(1 \mathrm{mg} \mathrm{l}^{-1}\right)\end{array}$ \\
\hline Mutant & $\begin{array}{l}\text { None } \\
\text { Acetate } \\
\text { Propionate } \\
\text { n-Butyrate } \\
\text { Isobutyrate }\end{array}$ & $\begin{array}{l}4 \\
3 \\
3 \\
2 \\
3\end{array}$ & $\begin{array}{c}184 \pm 30 \\
370 \pm 57 \\
302 \pm 1 \cdot 0 \\
\text { NG } \\
241 \pm 18\end{array}$ & $\begin{array}{c}102 \pm 3 \cdot 1 \\
99 \pm 3 \cdot 5 \\
271 \pm 11 \\
\mathrm{NG} \\
150 \pm 17\end{array}$ \\
\hline Wild-type & $\begin{array}{l}\text { None } \\
\text { Acetate } \\
\text { Propionate } \\
\text { Isobutyrate }\end{array}$ & $\begin{array}{l}4 \\
4 \\
3 \\
2\end{array}$ & $\begin{array}{l}75 \pm 2 \cdot 0 \\
80 \pm 1 \cdot 8 \\
98 \pm 2 \cdot 2 \\
91 \pm 3 \cdot 0\end{array}$ & $\begin{aligned} 73 & \pm 2.4 \\
82 & \pm 1.8 \\
122 & \pm 13.9 \\
87 & \pm 1.5\end{aligned}$ \\
\hline
\end{tabular}

NG, No growth observed.

monopalmitate (Tween 40), so that the cells did not need to synthesize palmitate. Growth was measured at different pantothenate concentrations with and without excess carnitine (Fig. 3), and at a fixed pantothenate concentration with varying carnitine concentrations (Fig. 4). Carnitine clearly stimulated the growth rate at each of the pantothenate concentrations but it did not increase the final cell yield. It was therefore concluded that the role of carnitine in this yeast was not to decrease the requirement for pantothenate or CoA. 


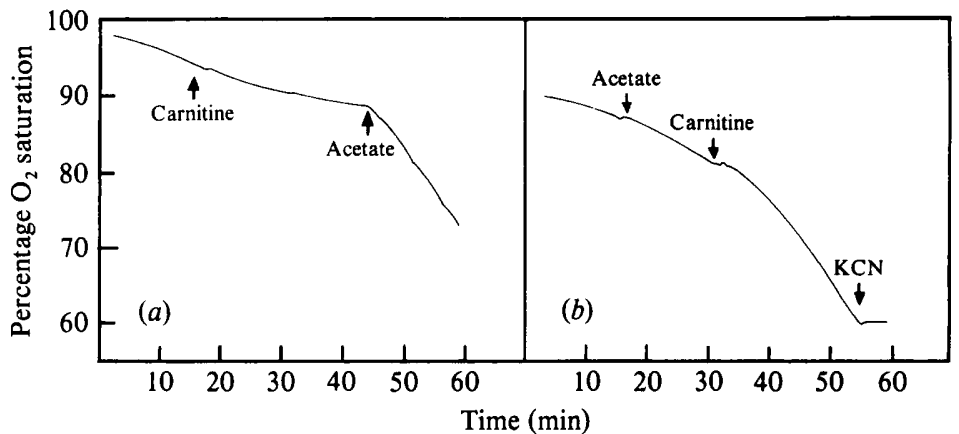

Fig. 5. Influence of acetate and carnitine on rates of oxygen utilization by $T$. bovina ATCC 26014 . The yeast was grown, harvested and suspended in salts medium to a concentration of $1.6 \times 10^{6} \mathrm{cells} \mathrm{ml}^{-1}$. Samples $(3 \mathrm{ml})$ were placed in the YSI Oxygen Monitor and equlilibrated to $37^{\circ} \mathrm{C}$. Samples of the same yeast suspension were used for runs $(a)$ and $(b)$. At the times indicated by the arrows, samples $(30 \mu l)$ of sodium acetate buffer $(\mathrm{pH} 5,0.05 \mathrm{M})$, DL-carnitine $(0.3 \mathrm{M})$ or $\mathrm{KCN}(0.5 \mathrm{M})$ were injected into the cell suspension.

Table 2. Oxygen utilization by $T$. bovina

The yeasts were grown in medium without carnitine, washed cell suspensions $(3 \mathrm{ml})$ were prepared and oxygen utilization was measured in the YSI Oxygen Monitor before and after addition of samples $(30 \mu \mathrm{l})$ of the appropriate fatty acid $(\mathrm{pH} 5,0.15 \mathrm{M})$, and $30 \mathrm{~min}$ after subsequent addition of DL-carnitine $(0.3 \mathrm{M}, 30 \mu \mathrm{l})$. Results of typical experiments are given. The respiration rate as a percentage of the corresponding basal value is shown in parentheses.

\begin{tabular}{|c|c|c|c|}
\hline \multirow[b]{2}{*}{$\begin{array}{c}\text { Test } \\
\text { compound }\end{array}$} & \multicolumn{3}{|c|}{$\begin{array}{c}\text { Oxygen utilization } \\
\text { (nmol O } \mathrm{h}^{-1} \text { per } 10^{6} \text { cells) }\end{array}$} \\
\hline & $\begin{array}{c}\text { Before } \\
\text { addition }\end{array}$ & $\begin{array}{c}+ \text { Test } \\
\text { compound }\end{array}$ & + Carnitine \\
\hline \multicolumn{4}{|l|}{ Expt $1^{*}$} \\
\hline Acetate & $17 \cdot 2$ & $28 \cdot 3(165)$ & $43 \cdot 6(253)$ \\
\hline Propionate & $15 \cdot 4$ & $12.6(82)$ & $7 \cdot 5(49)$ \\
\hline Isobutyrate & $14 \cdot 5$ & $8.0(55)$ & $2.5(17)$ \\
\hline n-Butyrate & $11 \cdot 7$ & $6 \cdot 2(53)$ & 3.4 (29) \\
\hline \multicolumn{4}{|l|}{ Expt 2} \\
\hline Acetate† & 68 & $157(232)$ & $156(230)$ \\
\hline Acetate* & 23 & $27(117)$ & $97(420)$ \\
\hline
\end{tabular}

* Carnitine-responsive mutant $T$. bovina ATCC 26014 was used.

† Wild-type T. bovina ATCC 22987 was used.

In order to test the hypothesis that carnitine facilitates the utilization of short-chain fatty acids, the yeast was grown in carnitine-free and -supplemented medium to which acetate had been added. Growth was inhibited by acetate in the absence of carnitine, but carnitine reversed this inhibition (Table 1). Growth inhibition by propionate or butyrate was not reversed by carnitine (Table 1). These results indicated that carnitine played a useful and possibly a major role in handling acetate in T. bovina ATCC 26014.

It has been suggested that carnitine acetyltransferase might function in transporting acetyl groups into T. bovina mitochondria (Emaus \& Bieber, 1983). In order to test this hypothesis the effect of carnitine on the respiration rate of the yeast was measured. Carnitine did not stimulate the endogenous respiration rate (Fig. $5 a$ ). When acetate was added to a suspension of cells respiring by using endogenous substrates the oxygen utilization rate increased slightly (Table 2), suggesting that acetate can enter the mitochondria even in the absence of carnitine, but addition of carnitine to this system resulted in a dramatic increase in oxygen utilization (Fig. $5 b$ ). In contrast, carnitine was not the limiting factor in oxygen utilization when glucose, pyruvate, or ethanol were the substrates. Similar experiments in which propionate, $n$-butyrate, or isobutyrate 
were added to cells of $T$. bovina ATCC 26014 demonstrated that these acids inhibited oxygen utilization. Acetate, added in equimolar amounts with propionate, n-butyrate or isobutyrate reversed their inhibitory effects on oxygen utilization.

Although T. bovina ATCC 26014 has been described as 'carnitine requiring' (Travassos \& Sales, 1974) it would be more accurate to term it 'carnitine responsive' because its growth rate is increased by carnitine but there is no absolute carnitine requirement (Table 1). The growth of the wild-type was not stimulated by carnitine (Table 1). When both strains were grown in medium lacking carnitine, neither strain contained detectable amounts of carnitine or of its derivatives (Fig. 1b). There is therefore no evidence that either strain is capable of biosynthesizing carnitine. When grown in the presence of carnitine both strains contained free carnitine and its acetyl and propionyl derivatives (Fig. $1 b$ ). Both strains therefore exhibit carnitine acetyltransferase activity. A clue to the function of carnitine may be found in the difference between the mutant and wild-type strains in their behaviour in the presence of acetate: growth of the mutant strain was inhibited in the presence of acetate in the absence of carnitine but the wild-type was not subject to this inhibition (Table 1). Oxygen utilization of the wild-type was rapidly and considerably stimulated by acetate in the absence of carnitine, and carnitine supplementation caused no further stimulation (Table 2). In contrast, respiration of the mutant strain was not dramatically increased by acetate unless carnitine was present. These results suggest two mechanisms for handling of acetate by $T$. bovina mitochondria, one of which requires carnitine and is the limiting factor in oxidation of acetate by the mutant strain, and a more rapid mechanism, used by the wild-type, which does not require carnitine.

\section{DISCUSSION}

Carnitine has long been known to be a growth factor for the mealworm Tenebrio molitor (Fraenkel \& Friedman, 1957) as well as for the mutant strain of Torulopsis bovina (Travassos \& Sales, 1974). In mammalian systems extracts of various organs have been shown to contain carnitine esters of short- and long-chain fatty acids (Pearson \& Tubbs, 1967). Carnitine palmitoyltransferase plays a major role in transporting long-chain acyl groups into mitochondria prior to $\beta$-oxidation (Fritz, 1963). The metabolic role of carnitine acetyltransferase has not been studied as intensively as that of the palmitoyltransferase.

Casillas \& Erickson (1975) suggested that in monkey spermatozoa, where the total carnitine concentration was 1000 times the total $\mathrm{CoA}$ concentration, carnitine acetyltransferase buffered the acetyl-CoA : CoA ratio. In my experiments (Fig. 3) the molar ratio of DL-carnitine to pantothenate in the medium was 481 when the concentration of pantothenate was $5 \mathrm{ng} \mathrm{ml}^{-1}$ and 160 when it was $15 \mathrm{ng} \mathrm{ml}^{-1}$. Under these conditions carnitine stimulated growth rate without increasing cell yield. It was concluded that, under the conditions described, carnitine did not exert a sparing action on the pantothenate (or $\mathrm{CoA}$ ) supply of $T$. bovina. The stimulating effect on growth rate must have been due to some other function of carnitine.

The results presented here indicate that the growth stimulatory effect of carnitine may be related to its ability to facilitate transfer of acetyl groups into the mitochondrial matrix. Acetyl group transfer through inner mitochondrial membranes has been studied mainly with regard to transfer from the mitochondria to the cytoplasm. The major means of doing this has been shown to be transfer of citrate out of the mitochondrion, followed by its cleavage to oxalacetate and acetyl-CoA. Kohlhaw \& Tan-Wilson (1977) reported that the enzyme required to catalyse this reaction is absent in the yeast Saccharomyces cerevisiae. Because the enzyme required for formation of acetylcarnitine is present in large amounts in this yeast, Kohlaw \& Tan-Wilson (1977) suggested that the carnitine acetyltransferase might play a major role in transfer of acetyl groups across the mitochondrial membrane. Evidence presented here that carnitine increased the rate of oxidation of acetate by the mutant strain of $T$. bovina suggested that carnitine acetyltransferase was the limiting factor in transport of acetyl groups into mitochondria. Since carnitine stimulated growth under anaerobic as well as aerobic conditions (Emaus \& Bieber, 1983) the effect of carnitine on acetyl transport in this strain must involve metabolic pathways other than respiration. 
Previous work from this laboratory has shown that growth of the mutant strain of $T$. bovina is stimulated by L-arginine as well as by carnitine (Lewin et al., 1981). Glutamate, ornithine and citrulline, known intermediates in the arginine synthesis pathway, also stimulated growth (Golan \& Lewin, 1981). This indicated that carnitine might play a role in arginine biosynthesis. Stimulation of growth of the yeast by glutamate was also reported by Emaus \& Bieber (1983), who showed that the label from $\left[{ }^{14} \mathrm{C}\right]$ acetylcarnitine is incorporated into glutamate and arginine. The acetyl groups transported by the carnitine acetylcarnitine system might also be used for other metabolic purposes. Propionylcarnitine and traces of 4-carbon acylcarnitines in the cells may be products of branched-chain amino acid catabolism (Bremer, 1983; Bieber \& Choi, 1977).

Comparison with the mutant strain indicated that the wild-type $T$. bovina has an efficient mechanism for transporting acetyl groups into mitochondria that does not require carnitine for its operation. A defect in this system in the mutant might explain its slow growth in the absence of carnitine. Emaus \& Bieber (1983) have suggested that free acetate may have been transported into the mitochondrion and a defect in intramitochondrial acetyl-CoA synthetase might explain the differences between the strains. Further research will be required to establish which means of acetyl group transfer is used by wild-type Torulopsis bovina in the absence of carnitine.

We acknowledge the technical assistance of $\mathrm{Mr}$ Amos Gabsu and of Joshua H. Lewin in conducting some of the yeast growth studies. This project was supported, in part, by a grant from the Office of the Chief Scientist, Ministry of Health, State of Israel.

\section{REFERENCES}

BIEBER, L. L. \& CHOI, Y. R. (1977). Isolation and identification of aliphatic short-chain acylcarnitines from beef heart: possible role for carnitine in branched-chain amino acid metabolism. Proceedings of the National Academy of Sciences of the United States of America 74, 2795-2798.

Bieber, L. L., Sabourin, P., Fogle, P. J., Valkner, K. \& LutNick, R. (1980). Studies on the formation and utilization of isobutyrylcarnitine. In Carnitine Biosynthesis, Metabolism and Functions, pp. 159-169. Edited by R. A. Frenkel \& J. D. McGarry. New York: Academic Press.

Bremer, J. (1983). Carnitine metabolism and functions. Physiological Reriews 63, 1421-1480.

Casillas, E. R. \& ERICKson, B. J. (1975). The role of carnitine in spermatozoan metabolism: substrateinduced elevations in the acetylation state of carnitine and coenzyme $A$ in bovine and monkey spermatozoa. Biology of Reproduction 12, 275-283.

Fmaus, R. K. \& Bieber, L. L. (1983). A biosynthetic role for carnitine in the yeast Torulopsis borina. Journal of Biological Chemistry 258, 13160-13165.

Fraenkel, G. \& Friedman, S. (1957). Carnitine. Vitamins and Hormones 15, 73 118.

FrITZ. 1. B. (1963). Carnitine and its role in fatty acid metabolism. Adrances in Lipid Research 1, 285334.

Golan, R. \& Lewin, L. M. (1981). Arginine and carnitine requirements of Torulopsis borina
ATCC 26014. Israel Journal of Medical Sciences 17 , 484.

Kohlhaw, G. B. \& Tan-Wilson, A. (1977). Carnitine acetyltransferase : candidate for the transfer of acetyl groups through the mitochondrial membrane of yeast. Journal of Bacteriology 129, 1159-1161.

LEWIN, L. M. \& BIEBER, L. L. (1979). Paper chromatography and bioautography of L-carnitine ands its acyl esters. Analytical Biochemistry 96, 322-325.

Lewin, L. M. \& Bieber, L. L. (1979). Paper chromatography and bioautography of L-carnitine and its acyl esters. Analytical Biochemistry 96, 322-325.

Sciences, Abstract c175.

Lewin, L. M., Orenstein, H., Nebel, L. \& Emaus, R. (1981). Bioautography of carnitine derivatives: compounds in human semen possessing biological activity for a carnitine-requiring mutant of the yeast, Torulopsis horina. Clinical Biochemistry 14, 305-308.

Pearson, D. J. \& Tubbs, P. K. (1967). Carnitine and derivatives in rat tissues. Biochemical Journal 105, 953.963

Snoswell, A. M. \& Koundakjian, P. P. (1972). Relationships between carnitine and coenzyme A esters in tissues of normal and alloxan-diabetic sheep. Biochemical Journal 127, 133-141.

Travassos, L. R. \& Sales, C. O. (1974). Microbiological assay of carnitine. Analytical Biochemistry $\mathbf{5 8}$, 485-499. 